\title{
ÁRVORES DE UM FRAGMENTO FLORESTAL URBANO EM SANTA CATARINA, SUL DO BRASIL: FLORÍSTICA E ESTRUTURA
}

\author{
TREES OF A URBAN FOREST FRAGMENT: FLORISTIC AND STRUCTURE
}

\author{
Guilherme Alves Elias ${ }^{1}$ Humberto de Bona Martins ${ }^{2}$ Alexandra Rocha Vinholes ${ }^{3}$ Birgit Harter Marques ${ }^{4}$ \\ Vanilde Citadini-Zanette ${ }^{4}$ Robson dos Santos ${ }^{4}$
}

\begin{abstract}
RESUMO
Este trabalho teve como objetivo realizar levantamento florístico e estrutural em um fragmento florestal urbano no Parque Ecológico Municipal José Milanese, no município de Criciúma, Santa Catarina, sul do Brasil, enfatizando a importância deste fragmento para a conservação de espécies ameaçadas. O levantamento consistiu na instalação de 100 parcelas contíguas de $10 \times 10 \mathrm{~m}$ em Floresta Ombrófila Densa Submontana, sendo amostradas todas as espécies arborescentes com diâmetro à altura do peito (DAP) $\geq 5 \mathrm{~cm}$. Foram registradas 137 espécies, sendo Myrtaceae a família mais rica. Cryptocarya moschata Nees \& Mart. apresentou o maior valor de importância, principalmente pelo maior diâmetro de seus caules, seguida por Psychotria vellosiana Benth., Myrcia pubipetala Miq. e Guatteria australis A.St.-Hil., evidenciando a possibilidade de suas utilizações em programas de restauração ecológica em fragmentos florestais da região. Conclui-se que o fragmento estudado apresenta elevada riqueza específica, quando comparado com outros na região, tornando-o uma importante fonte de propágulos para áreas adjacentes. Além disso, o conhecimento produzido a partir deste estudo poderá fornecer alternativas de uso e manejo em áreas similares, ou mesmo, ambientes florestais alterados, de forma geral.
\end{abstract}

Palavras-chave: Biodiversidade; Floresta Atlântica; restauração florestal.

\begin{abstract}
This study aimed to carry out a floristic and structural survey of an urban forest fragment at 'Parque Ecológico Municipal José Milanese', in the municipality of Criciúma, Santa Catarina State, southern Brazil, emphasizing the importance of this fragment for the conservation of endangered species. Survey consisted in the installation of 100 contiguous plots of $10 \times 10 \mathrm{~m}$ in Submontane Dense Ombrophilous Forest, all tree species with a diameter at breast height (DBH) $\geq 5 \mathrm{~cm}$ were sampled. One hundred and thirty-seven (137) species were recorded, being Myrtaceae the richest family. Cryptocarya moschata Nees \& Mart. presented the highest value of importance, mainly due to the larger diameter of its stems, followed by Psychotria vellosiana Benth., Myrcia pubipetala Miq. and Guatteria australis A.St.-Hil., evidencing the possibility of their use in ecological restoration programs in forest fragments of the region. We concluded that the fragment studied has a high specific richness when compared to others in the region, making it an important source of propagules for adjacent areas. In addition, the knowledge produced from this study may provide alternatives for use and management in similar areas, or even altered forest environments, in general.
\end{abstract}

Keywords: Atlantic Rainforest; biodiversity; forest restoration.

1 Biólogo, Dr., Herbário Pe. Dr. Raulino Reitz (CRI), Universidade do Extremo Sul Catarinense, Av. Universitária, 1105, Bairro Universitário, CEP 88806-000, Criciúma (SC), Brasil. guilherme@unesc.net

2 Biólogo, MSc., Herbário Pe. Dr. Raulino Reitz (CRI), Universidade do Extremo Sul Catarinense, Av. Universitária, 1105, Bairro Universitário, CEP 88806-000, Criciúma (SC), Brasil. humberto_morrinho@hotmail.com

3 Bióloga, Dra., Laboratório de Interação Animal-Planta, Universidade do Extremo Sul Catarinense, Av. Universitária, 1105, Bairro Universitário, CEP 88806-000, Criciúma (SC), Brasil. arvinholes@hotmail.com

4 Biólogo, Dr., Professor do Programa de Pós-Graduação em Ciências Ambientais (PPGCA), Universidade do Extremo Sul Catarinense, Av. Universitária, 1105, Bairro Universitário, CEP 88806-000, Criciúma (SC), Brasil.bhm@unesc.net / vcz@unesc.net / rsa@unesc.net

Recebido para publicação em 16/10/2015 e aceito em 23/08/2017

Ci. Fl., v. 28, n. 4, out. - dez., 2018 


\section{INTRODUÇ̃̃O}

Dentre as alterações que as florestas estão sujeitas, em nível mundial, destaca-se a fragmentação, que resulta em porções de vegetação progressivamente menores, isoladas por áreas ocupadas pelo desenvolvimento agrícola, industrial e urbano. A fragmentação de habitat é o processo pelo qual áreas contínuas naturais são reduzidas, resultando em dois ou mais fragmentos. Metzger (2001) definiu fragmento como uma mancha originada por fragmentação, ou seja, por subdivisão, promovida pelo homem, de uma unidade que inicialmente apresentava-se com forma contínua, podendo ocasionar, também, a ruptura dos fluxos gênicos entre as populações presentes nesse habitat (KAGEYAMA; GANDARA; SOUZA, 1998).

Os fragmentos florestais urbanos ou próximos às cidades são cada vez mais comuns. Esses fragmentos permitem manter a biodiversidade regional, pois, ali, plantas, insetos e outros animais ainda encontram abrigo e alimento (MORELATTO; LEITÃO-FILHO, 1995). As árvores dentro desses fragmentos podem ser importantes fontes de propágulos ou sítios de pousio para a fauna dispersora, processo crucial para que populações de plantas e animais em remanescentes menores possam se manter ou se reestabelecer (SCARIOT et al., 2003).

Nas florestas urbanas são evidentes os efeitos do histórico de exploração e da contínua expansão da população humana, que resultaram na formação de pequenos fragmentos de vegetação remanescente que se encontram isolados nos centros urbanos (HULTMAN, 1976) e que, atualmente, fazem parte de Unidades de Conservação. Gómez-Pompa e Wiechers (1979) já alertavam que os ecossistemas florestais primários seriam exceções e estariam confinados em Unidades de Conservação que, devido ao longo tempo de isolamento, poderiam abrigar espécies endêmicas, devendo ser considerados como de alta prioridade para a conservação. Entretanto, Britez et al. (2003) relataram que as Unidades de Conservação são verdadeiras ilhas que, isoladas em meio à paisagem, sofrem deterioração progressiva de seus ambientes, na maioria das vezes, a partir das bordas, em face da pressão antrópica e das perturbações naturais, mas que, fisionomicamente, podem aparentar uma comunidade original (RANKIN-DE-MERONA; ACKERLY, 1987). Embora fragilizados, tais fragmentos remanescentes comportam elevado valor ambiental, econômico, paisagístico e social, pois ainda conservam características próprias de um meio não urbano (PRIMACK; RODRIGUES, 2001).

Com a realização de levantamentos da biota em áreas urbanas é possível perceber que os diferentes estágios sucessionais que os fragmentos se encontram são decorrentes dos diversos padrões de desenvolvimento social e econômico nacionais, regionais e locais (FISZON et al., 2003), que os alteraram em sua essência. A conservação de áreas de vegetação nativa depende, na maioria das vezes, da sensibilidade e apoio da população, que deve sentir-se responsável em mantê-la e compreender a importância de sua preservação, tornando o conhecimento gerado pelas pesquisas mais acessível ao público em geral (MORELLATO; LEITÃO-FILHO, 1995). À conservação destas áreas somam-se também alguns benefícios psicológicos, como a sensação de paz, de serenidade, de liberdade e a promoção de saúde física (MILLER, 2007), além da percepção de locais confortáveis atribuídos à presença da natureza (DACANAL; LABAKI; SILVA, 2010).

Em Santa Catarina, $81 \%$ do território era coberto por florestas, que, atualmente, está reduzida a $29 \%$ de sua área original, que se encontra altamente fragmentada, com mais de $80 \%$ dos remanescentes com até 50 ha (VIBRANS et al., 2012). Entre as tipologias florestais do estado, a Floresta Ombrófila Densa foi considerada como a mais complexa e heterogênea da região sul do país, constatado pelas inúmeras comunidades e associações (LEITE; KLEIN, 1990). Este ecossistema ainda é o mais conservado, com um percentual de $40 \%$ remanescente, dos $29 \%$ restantes de cobertura florestal do estado (VIBRANS et al., 2012).

Neste contexto, este estudo teve como objetivo realizar levantamento florístico e estrutural da vegetação arborescente do Parque Ecológico Municipal José Milanese, um fragmento florestal urbano do município de Criciúma, Santa Catarina. Espera-se que este estudo forneça subsídios para a gestão de ambientes florestais urbanos, assim como para programas de restauração ambiental em áreas similares.

\section{MATERIAL E MÉTODO}

O presente estudo foi desenvolvido em um fragmento urbano de Floresta Ombrófila Densa Submontana $\left(28^{\circ} 48^{\prime} \mathrm{S}\right.$ e $49^{\circ} 25^{\prime} \mathrm{W}$, altitude de $\left.34 \mathrm{~m}\right)$ em estágio sucessional avançado de regeneração natural, 
ratificado por relato de antigo proprietário que declarou ocorrer corte seletivo, nos anos 1980, de palmiteiros (Euterpe edulis Mart.) e de outras espécies de interesse madeireiro. O fragmento florestal possui 5,2 ha e está inserido na área total do Parque Ecológico Municipal José Milanese (PEMJM), de 7,7 ha, localizado em área periférica no município de Criciúma, Santa Catarina (Figura 1).

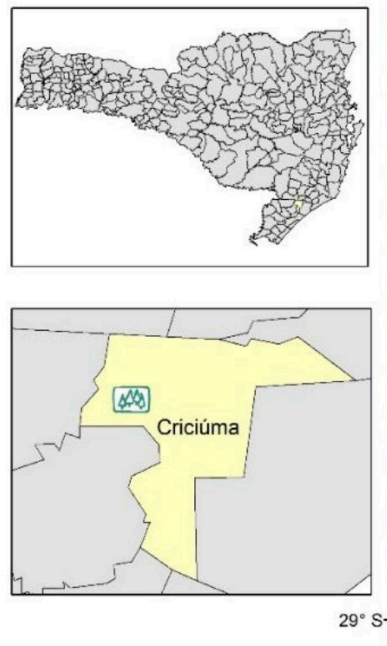

Legenda

Parque Ecológico Municipal José Milanese Unidade Amostral

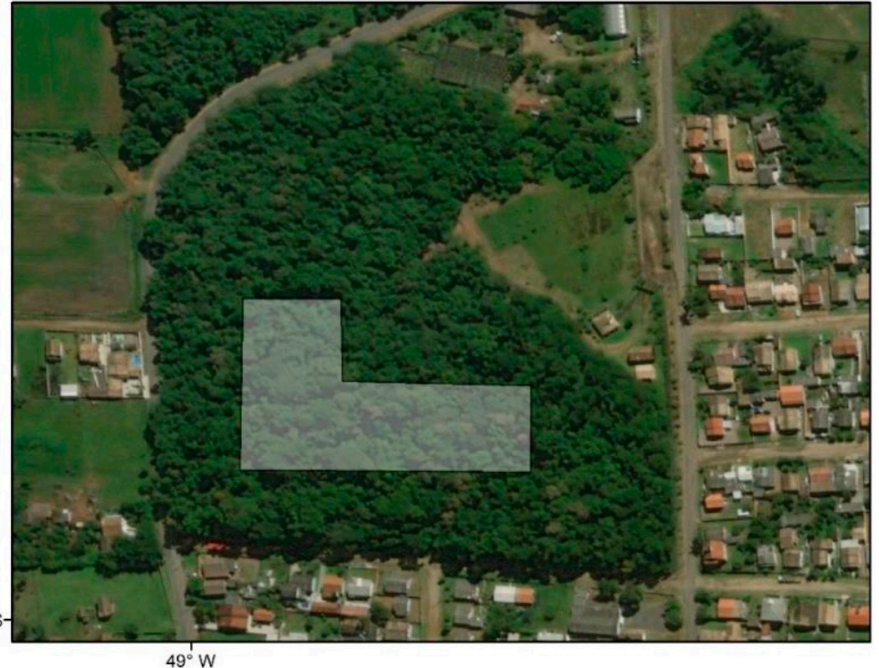

$49^{\circ} \mathrm{W}$
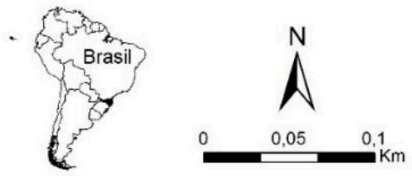

Author: Guilherme Alves Elias Service Layer Credits. Bing Maps Coordinate System: GCS WGS 1984

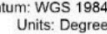

FIGURA 1: Localização e delimitação da amostra em um fragmento urbano de Floresta Ombrófila Densa Submontana no município de Criciúma, estado de Santa Catarina, sul do Brasil.

FIGURE 1: Location and sampling distribution in an urban forest fragment of Submontane Dense Ombrophilous Forest in the municipality of Criciúma, Santa Catarina State, southern Brazil.

O clima da região, segundo Köppen, é subtropical úmido, sem estação seca definida e com verão quente (Cfa) (ALVARES et al., 2013). A precipitação pluviométrica anual pode variar de 1.220 a $1.660 \mathrm{~mm}$, com o total anual de dias de chuva entre 102 e 150 dias. A umidade relativa do ar varia de 81 a $82 \%$ (EMPRESA DE PESQUISA AGROPECUÁRIA E DE EXTENSÃO RURAL DE SANTA CATARINA, 2001). Os solos encontrados na região são classificados como Argissolos (DUFLOTH et al., 2005).

Para o estudo da comunidade arborescente, utilizou-se o método de parcelas contíguas (MUELLER-DOMBOIS; ELLENBERG, 2002), que foram demarcadas em bloco em área mais conservada no interior do fragmento florestal do Parque, para evitar o efeito de borda. Foi estabelecido como amostragem 1 ha, subdividido em 100 parcelas de $10 \times 10 \mathrm{~m}$. A coleta do material botânico foi realizada dentro da área amostral e todos os indivíduos arborescentes com diâmetro à altura do peito (DAP) $\geq 5 \mathrm{~cm}$ foram identificados, mensurados e tiveram suas alturas estimadas. A delimitação familiar seguiu as propostas de Smith et al. (2008) para as samambaias, e Angiosperm Phylogeny Group (2016), para as angiospermas. A suficiência amostral foi determinada por meio de uma curva de rarefação, realizada utilizando-se 999 permutações, com o auxílio do programa Past, versão 3.16. Com os dados obtidos calcularam-se os descritores fitossociológicos usuais para as espécies encontradas: frequência, densidade e dominância relativas e o valor de importância (VI), de acordo com Mueller-Dombois e Ellenberg (2002). Para melhor compreender a estrutura da floresta foram elaborados histogramas com a distribuição dos indivíduos da comunidade nas classes de diâmetro e de altura.

A comparação florística foi feita entre a comunidade arborescente amostrada no presente estudo e os levantamentos florísticos realizados em outros fragmentos florestais localizados no perímetro urbano do sul de Santa Catarina, como o de Pacheco (2010), em Criciúma, e o estudo de Citadini-Zanette et al. 
(2014), no município de Turvo. Além disso, foram realizadas comparações com outros estudos florísticos e fitossociológicos em áreas não urbanas do sul do Estado. Utilizou-se o índice qualitativo de similaridade de Jaccard (IJs) para comparar os dados florísticos entre as comunidades, além do índice de diversidade (MAGURRAN, 2004) e de equabilidade (PIELOU, 1975).

As espécies foram classificadas em grupos ecológicos, seguindo-se a proposta de Ferreti et al. (1995), que dividem as espécies em pioneiras (Pio), secundárias iniciais (Sin), secundárias tardias (Sta) e clímax (Cli). Para essa classificação, utilizou-se como base a "Flora Ilustrada Catarinense" (REITZ, 1965), além de observações em campo. Para avaliar o risco de extinção, as espécies foram observados os critérios estabelecidos pela International Union for Conservation of Nature (IUCN), descritos no "Livro Vermelho da Flora do Brasil" (MARTINELLI; MORAES, 2013).

\section{RESULTADOS E DISCUSSÃO}

Nas 100 parcelas foram amostrados 1.412 indivíduos de 137 espécies arborescentes, pertencentes a 45 famílias botânicas (Tabela 1). Das famílias amostradas, 23 (51\%) estão representadas por apenas uma espécie, seis (13\%) por duas e outras sete (17\%) por três espécies. As famílias com maior riqueza específica foram Myrtaceae (30 espécies), Lauraceae (14), Fabaceae e Rubiaceae (sete), Meliaceae (seis), Annonaceae e Moraceae (cinco), e Melastomataceae e Primulaceae (quatro). O gênero com maior riqueza específica foi Myrcia, com 11 espécies, seguido por Eugenia, com oito. A curva de rarefação (Figura 2) indicou que a amostra atingiu suficiência, visto que a linha tendeu à estabilidade em 100 parcelas, portanto, a adição de novas espécies não alteraria significativamente o número de espécies observadas (KERSTEN; GALVÃO, 2011).

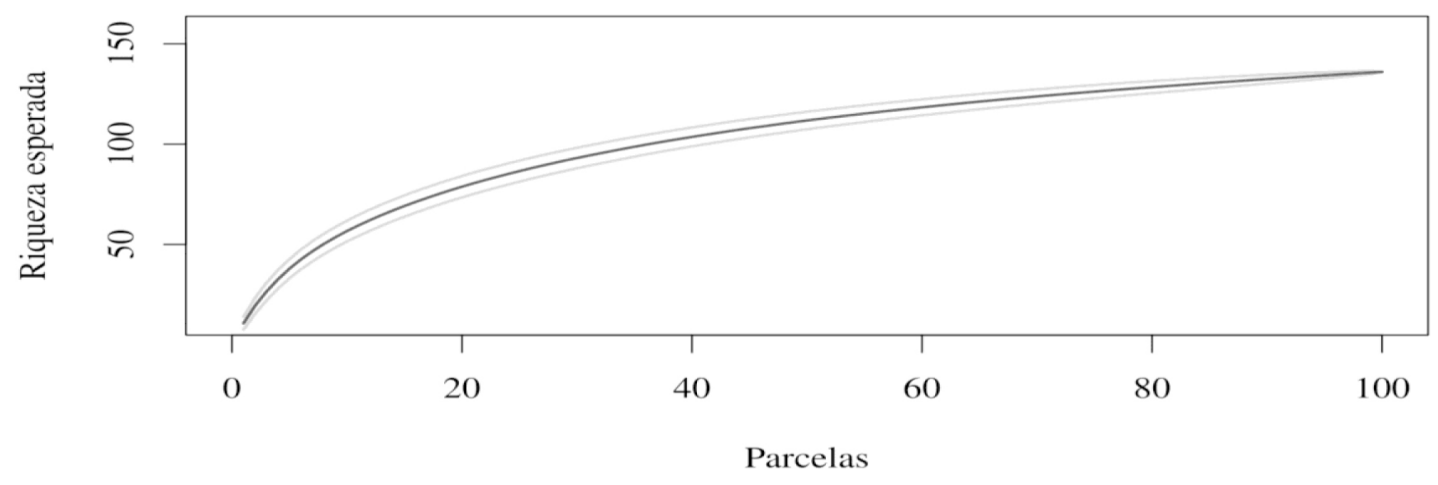

FIGURA 2: Curva de rarefação para a representação da riqueza das espécies amostradas em um fragmento urbano de Floresta Ombrófila Densa Submontana no município de Criciúma, estado de Santa Catarina, sul do Brasil.

FIGURE 2: Rarefaction curve for representation of the richness of the species sampled in an urban fragment of Submontane Dense Ombrophilous Forest in the municipality of Criciúma, Santa Catarina State, southern Brazil.

A classificação sucessional de espécies florestais tem sido um ponto polêmico em estudos de florestas, no entanto, auxilia na compreensão da dinâmica florestal e na adoção de práticas adequadas de manejo e restauração de florestas (MORELATTO; LEITÃO FILHO, 1995). Pela abundância e riqueza específica das categorias representadas pelo grupo avançado de sucessão ecológica (Tabela 1), pode-se sugerir que o fragmento florestal não esteja sofrendo perturbações recentes. O grupo que caracteriza o estágio inicial (pioneiras e secundárias iniciais) representou somente 19\% do número total de indivíduos e 33\% das espécies amostradas. Observou-se que, proporcionalmente, existe variação na relação entre o número de espécies e de indivíduos arborescentes para os grupos ecológicos, com aumento da representatividade das espécies de final de sucessão. 
TABELA 1: Estrutura fitossociológica, classificação por grupo ecológico e categorias de ameaça das espécies arborescentes amostradas em um fragmento urbano de Floresta Ombrófila Densa Submontana no município de Criciúma, estado de Santa Catarina, sul do Brasil.

TABLE 1: $\quad$ Phytosociological structure; classification by ecological group and threat categories of the tree species sampled in an urban forest fragment of Submontane Dense Ombrophilous Forest in the municipality of Criciúma, Santa Catarina State, southern Brazil.

\begin{tabular}{|c|c|c|c|c|c|c|c|}
\hline Espécie & $\mathrm{H}$ & FR & DR & DoR & VI & GE & $\mathrm{CA}$ \\
\hline Cryptocarya moschata Nees \& Mart. & 18 & 3,63 & 4,53 & 6,67 & 14,84 & Cli & $\mathrm{NE}$ \\
\hline Psychotria vellosiana Benth. & 16 & 3,26 & 3,47 & 4,83 & 11,56 & Sta & NE \\
\hline Myrcia pubipetala Miq. & 15 & 4,29 & 5,52 & 1,69 & 11,5 & Sta & LC \\
\hline Guatteria australis A.St.-Hil. & 15 & 3,36 & 3,9 & 3,83 & 11,08 & Sta & $\mathrm{LC}$ \\
\hline Alsophila setosa Kaulf. & 7 & 2,24 & 6,44 & 2,1 & 10,78 & Cli & NE \\
\hline Matayba guianensis Aubl. & 18 & 2,05 & 1,77 & 6,63 & 10,45 & Sta & NE \\
\hline Aspidosperma parvifolium A.DC. & 20 & 2,05 & 1,91 & 6,26 & 10,23 & Sta & NE \\
\hline Cabralea canjerana (Vell.) Mart. & 16 & 3,36 & 3,26 & 1,77 & 8,38 & Sta & NE \\
\hline Sorocea bonplandii (Baill.) W.C.Burger et al. & 10 & 3,08 & 3,9 & 0,95 & 7,92 & Sta & NE \\
\hline Alchornea triplinervia (Spreng.) Müll.Arg. & 16 & 1,86 & 1,56 & 4,35 & 7,77 & $\operatorname{Sin}$ & $\mathrm{NE}$ \\
\hline Ocotea urbaniana $\mathrm{Mez}$ & 19 & 2,05 & 1,77 & 3,94 & 7,76 & Cli & NE \\
\hline Magnolia ovata (A.St.-Hil.) Spreng. & 18 & 2,61 & 2,27 & 2,62 & 7,49 & Sta & NE \\
\hline Myrcia splendens (Sw.) DC. & 14 & 2,89 & 3,19 & 1,13 & 7,21 & $\operatorname{Sin}$ & NE \\
\hline Casearia sylvestris Sw. & 14 & 2,61 & 2,48 & 1,91 & 7 & Pio & NE \\
\hline Meliosma sellowii Urb. & 17 & 1,58 & 1,84 & 3,4 & 6,83 & Sta & NE \\
\hline Ocotea indecora (Schott) Mez & 17 & 1,86 & 1,56 & 3,39 & 6,82 & Cli & NE \\
\hline $\begin{array}{l}\text { Marlierea eugeniopsoides } \\
\text { (D.Legrand \& Kausel) D.Legrand }\end{array}$ & 19 & 2,52 & 2,76 & 1,31 & 6,59 & Cli & $\mathrm{NE}$ \\
\hline Sloanea guianensis (Aubl.) Benth. & 12 & 2,24 & 2,2 & 1,21 & 5,64 & Cli & $\mathrm{NE}$ \\
\hline Rudgea jasminoides (Cham.) Müll.Arg. & 7 & 2,42 & 2,69 & 0,42 & 5,54 & Cli & NE \\
\hline Protium kleinii Cuatrec. & 14 & 1,86 & 1,77 & 1,61 & 5,25 & Cli & LC \\
\hline Duguetia lanceolata A.St.-Hil. & 17 & 1,12 & 0,92 & 3 & 5,04 & Sta & LC \\
\hline Eugenia neoverrucosa Sobral & 11 & 2,14 & 1,98 & 0,77 & 4,9 & Sta & $\mathrm{NE}$ \\
\hline Guapira opposita (Vell.) Reitz & 10 & 1,86 & 1,7 & 1,31 & 4,87 & $\operatorname{Sin}$ & NE \\
\hline Piptadenia gonoacantha (Mart.) J.F.Macbr. & 17 & 0,93 & 0,71 & 2,62 & 4,26 & Pio & LC \\
\hline Nectandra oppositifolia Nees & 17 & 1,49 & 1,27 & 1,32 & 4,09 & Sta & NE \\
\hline Trichilia lepidota Mart. & 14 & 1,68 & 1,63 & 0,46 & 3,77 & Cli & LC \\
\hline Ilex paraguariensis A.St.-Hil. & 16 & 1,4 & 1,27 & 0,94 & 3,61 & $\mathrm{Cli}$ & $\mathrm{LC}$ \\
\hline Cupania vernalis Cambess. & 18 & 0,75 & 0,64 & 2,07 & 3,45 & Sin & NE \\
\hline Calyptranthes lucida Mart. ex DC. & 16 & 1,4 & 1,49 & 0,5 & 3,38 & Sta & $\mathrm{NE}$ \\
\hline Pseudobombax grandiflorum (Cav.) A.Robyns & 16 & 1,12 & 0,99 & 1,19 & 3,3 & Sta & LC \\
\hline Ocotea puberula (Rich.) Nees & 17 & 0,47 & 0,42 & 2,34 & 3,24 & Sta & NT \\
\hline Mollinedia schottiana (Spreng.) Perkins & 8 & 1,4 & 1,27 & 0,38 & 3,05 & Cli & NE \\
\hline Tetrorchidium rubrivenium Poepp. & 16 & 0,75 & 0,57 & 1,73 & 3,04 & Sin & LC \\
\hline Endlicheria paniculata (Spreng.) J.F.Macbr. & 13 & 1,4 & 1,27 & 0,35 & 3,03 & Sta & NE \\
\hline Ocotea odorifera (Vell.) Rohwer & 14 & 0,65 & 0,5 & 1,7 & 2,85 & Sta & EN \\
\hline Guarea macrophylla Vahl & 8 & 1,21 & 1,13 & 0,4 & 2,75 & Cli & $\mathrm{NE}$ \\
\hline
\end{tabular}


TABELA 1: Continua...

TABLE 1 Continued...

\begin{tabular}{|c|c|c|c|c|c|c|c|}
\hline Espécie & $\mathrm{H}$ & FR & DR & DoR & VI & GE & $\mathrm{CA}$ \\
\hline Cedrela fissilis Vell. & 17 & 0,84 & 0,64 & 1,06 & 2,54 & Sta & $\mathrm{VU}$ \\
\hline Cecropia glaziovii Snethl. & 18 & 0,75 & 0,57 & 1,09 & 2,4 & Pio & $\mathrm{NE}$ \\
\hline Aspidosperma australe Müll.Arg. & 17 & 0,56 & 0,42 & 1,25 & 2,24 & Cli & LC \\
\hline Faramea montevidensis (Cham. \& Schltdl.) DC. & 11 & 0,93 & 0,99 & 0,2 & 2,13 & Cli & $\mathrm{NE}$ \\
\hline $\begin{array}{l}\text { Lonchocarpus cultratus (Vell.) } \\
\text { A.M.G.Azevedo \& H.C.Lima }\end{array}$ & 14 & 0,93 & 0,71 & 0,34 & 1,98 & Sin & $\mathrm{NE}$ \\
\hline Aspidosperma tomentosum Mart. & 13 & 0,84 & 0,64 & 0,4 & 1,87 & $\operatorname{Sin}$ & NE \\
\hline Chrysophyllum inornatum Mart. & 13 & 0,75 & 0,71 & 0,4 & 1,85 & Cli & $\mathrm{LC}$ \\
\hline Hieronyma alchorneoides Allemão & 16 & 0,56 & 0,42 & 0,83 & 1,81 & $\operatorname{Sin}$ & $\mathrm{NE}$ \\
\hline Nectandra membranacea (Sw.) Griseb. & 14 & 0,65 & 0,57 & 0,35 & 1,57 & Sta & $\mathrm{NE}$ \\
\hline Inga sessilis (Vell.) Mart. & 16 & 0,75 & 0,57 & 0,26 & 1,57 & $\operatorname{Sin}$ & $\mathrm{NE}$ \\
\hline Sloanea monosperma Vell. & 16 & 0,56 & 0,42 & 0,57 & 1,55 & Cli & $\mathrm{NE}$ \\
\hline Vernonanthura discolor (Spreng.) H.Rob & 16 & 0,47 & 0,35 & 0,66 & 1,48 & Pio & NE \\
\hline Annona neosericea H.Rainer & 15 & 0,47 & 0,42 & 0,55 & 1,45 & Sta & $\mathrm{NE}$ \\
\hline Symplocos trachycarpos Brand & 16 & 0,19 & 0,14 & 1,03 & 1,36 & Sin & $\mathrm{NE}$ \\
\hline Piptocarpha tomentosa Baker & 17 & 0,28 & 0,21 & 0,87 & 1,36 & Pio & $\mathrm{NE}$ \\
\hline Aniba firmula (Nees \& Mart.) Mez & 15 & 0,37 & 0,35 & 0,62 & 1,35 & Sta & $\mathrm{NE}$ \\
\hline Eugenia stigmatosa DC. & 9 & 0,65 & 0,5 & 0,07 & 1,22 & Sta & $\mathrm{NE}$ \\
\hline Pisonia ambigua Heimerl & 10 & 0,37 & 0,28 & 0,51 & 1,17 & $\operatorname{Sin}$ & $\mathrm{LC}$ \\
\hline Euphorbiaceae & 18 & 0,37 & 0,28 & 0,51 & 1,16 & --- & --- \\
\hline Buchenavia kleinii Exell & 15 & 0,47 & 0,35 & 0,33 & 1,15 & Cli & $\mathrm{LC}$ \\
\hline Ocotea floribunda (Sw.) Mez & 13 & 0,28 & 0,28 & 0,53 & 1,1 & Sta & NE \\
\hline Neomitranthes cordifolia (D.Legrand) D.Legrand & 5 & 0,56 & 0,42 & 0,1 & 1,08 & Pio & VU \\
\hline Styrax acuminatus Pohl & 12 & 0,47 & 0,42 & 0,16 & 1,06 & Cli & $\mathrm{LC}$ \\
\hline Pera glabrata (Schott) Poepp. ex Baill. & 12 & 0,47 & 0,35 & 0,16 & 0,98 & Sta & NE \\
\hline Cordiera concolor (Cham.) Kuntze & 8 & 0,47 & 0,42 & 0,07 & 0,96 & Cli & $\mathrm{NE}$ \\
\hline Ocotea silvestris Vattimo-Gil & 15 & 0,37 & 0,28 & 0,29 & 0,95 & Cli & $\mathrm{LC}$ \\
\hline Schefflera morototoni (Aubl.) Maguire et al. & 16 & 0,28 & 0,21 & 0,43 & 0,92 & Sta & NE \\
\hline Myrceugenia myrcioides (Cambess.) O.Berg & 8 & 0,47 & 0,35 & 0,06 & 0,88 & Sta & $\mathrm{LC}$ \\
\hline Virola bicuhyba (Schott ex Spreng.) Warb. & 12 & 0,28 & 0,28 & 0,29 & 0,85 & Sta & EN \\
\hline Myrcia brasiliensis Kiaersk. & 12 & 0,28 & 0,42 & 0,14 & 0,85 & Sta & $\mathrm{NE}$ \\
\hline Annona cacans Warm. & 16 & 0,28 & 0,21 & 0,35 & 0,84 & Pio & $\mathrm{LC}$ \\
\hline Eugenia beaurepairiana (Kiaersk.) D.Legrand & 8 & 0,37 & 0,35 & 0,1 & 0,83 & Sta & $\mathrm{NE}$ \\
\hline Jacaranda puberula Cham. & 10 & 0,37 & 0,35 & 0,06 & 0,78 & Sin & LC \\
\hline Aiouea saligna Meisn. & 11 & 0,19 & 0,14 & 0,44 & 0,77 & $\operatorname{Sin}$ & $\mathrm{NE}$ \\
\hline Myrciaria floribunda (H.West ex Willd.) O.Berg & 9 & 0,37 & 0,28 & 0,11 & 0,76 & Cli & $\mathrm{LC}$ \\
\hline Myrcia glabra (O.Berg) D.Legrand & 9 & 0,37 & 0,28 & 0,1 & 0,75 & Sta & NE \\
\hline Trichilia casaretti C.DC. & 8 & 0,37 & 0,28 & 0,09 & 0,74 & Cli & $\mathrm{LC}$ \\
\hline Ficus luschnathiana (Miq.) Miq. & 15 & 0,28 & 0,28 & 0,16 & 0,72 & Sta & $\mathrm{NE}$ \\
\hline Miconia cinerascens Miq. & 8 & 0,37 & 0,28 & 0,06 & 0,72 & Pio & $\mathrm{NE}$ \\
\hline
\end{tabular}


TABELA 1: Continua...

TABLE 1 Continued..

\begin{tabular}{|c|c|c|c|c|c|c|c|}
\hline Espécie & $\mathrm{H}$ & FR & DR & DoR & VI & GE & CA \\
\hline Cinnamomum glaziovii (Mez) Kosterm. & 13 & 0,19 & 0,21 & 0,31 & 0,71 & Cli & $\mathrm{NE}$ \\
\hline Myrcia spectabilis DC. & 9 & 0,37 & 0,28 & 0,06 & 0,71 & Sta & NE \\
\hline Myrsine guianensis (Aubl.) Kuntze & 8 & 0,37 & 0,28 & 0,05 & 0,7 & $\operatorname{Sin}$ & $\mathrm{NE}$ \\
\hline Myrcia squamata (Mattos \& D.Legrand) Mattos & 8 & 0,37 & 0,28 & 0,05 & 0,7 & Sta & NE \\
\hline Byrsonima ligustrifolia A.Juss. & 16 & 0,19 & 0,14 & 0,35 & 0,68 & Sta & $\mathrm{NE}$ \\
\hline Maclura tinctoria (L.) D.Don ex Steud. & 16 & 0,09 & 0,07 & 0,48 & 0,64 & Pio & $\mathrm{NE}$ \\
\hline Chionanthus filiformis (Vell.) P.S.Green & 14 & 0,19 & 0,14 & 0,29 & 0,62 & Sta & $\mathrm{LC}$ \\
\hline Myrciaria plinioides D.Legrand & 7 & 0,28 & 0,28 & 0,04 & 0,61 & Sta & VU \\
\hline Ouratea parviflora (A.DC.) Baill. & 6 & 0,28 & 0,28 & 0,04 & 0,6 & Sta & $\mathrm{NE}$ \\
\hline Trema micrantha (L.) Blume & 12 & 0,28 & 0,21 & 0,1 & 0,6 & Pio & NE \\
\hline Myrcia richardiana (O.Berg) Mattos & 13 & 0,28 & 0,21 & 0,1 & 0,59 & Sta & NE \\
\hline Hirtella hebeclada Moric. ex DC. & 10 & 0,28 & 0,21 & 0,08 & 0,57 & Sta & NE \\
\hline Luehea divaricata Mart. \& Zucc. & 10 & 0,28 & 0,21 & 0,04 & 0,54 & Sin & NE \\
\hline Garcinia gardneriana (Planch. \& Triana) Zappi & 8 & 0,28 & 0,21 & 0,03 & 0,52 & Sta & $\mathrm{NE}$ \\
\hline Eugenia handroana D.Legrand & 9 & 0,28 & 0,21 & 0,03 & 0,52 & Sta & NE \\
\hline Lamanonia ternata Vell. & 9 & 0,28 & 0,21 & 0,03 & 0,52 & Pio & $\mathrm{NE}$ \\
\hline Chrysophyllum viride Mart. \& Eichler & 10 & 0,19 & 0,14 & 0,11 & 0,44 & Cli & NT \\
\hline Citronella paniculata (Mart.) R.A.Howard & 8 & 0,19 & 0,21 & 0,03 & 0,43 & Cli & $\mathrm{NE}$ \\
\hline Brosimum lactescens (S.Moore) C.C.Berg & 8 & 0,19 & 0,14 & 0,08 & 0,41 & Cli & $\mathrm{LC}$ \\
\hline Pouteria gardneriana (A.DC.) Radlk. & 15 & 0,19 & 0,14 & 0,05 & 0,38 & Sin & NE \\
\hline Picramnia parvifolia Engl. & 6 & 0,19 & 0,14 & 0,04 & 0,36 & Pio & LC \\
\hline Eugenia subterminalis DC. & 9 & 0,19 & 0,14 & 0,03 & 0,36 & Sta & $\mathrm{NE}$ \\
\hline Marlierea silvatica (O.Berg) Kiaersk. & 8 & 0,19 & 0,14 & 0,03 & 0,36 & Sta & NE \\
\hline Myrsine sp. & 10 & 0,19 & 0,14 & 0,03 & 0,35 & --- & --- \\
\hline Eugenia platysema O.Berg & 7 & 0,19 & 0,14 & 0,02 & 0,35 & Cli & LC \\
\hline Trichilia pallens C.DC. & 6 & 0,19 & 0,14 & 0,02 & 0,35 & Cli & LC \\
\hline Miconia sp. & 6 & 0,19 & 0,14 & 0,02 & 0,35 & ---- & --- \\
\hline Esenbeckia grandiflora Mart. & 6 & 0,19 & 0,14 & 0,01 & 0,34 & Sta & NE \\
\hline Zanthoxylum rhoifolium Lam. & 9 & 0,19 & 0,14 & 0,01 & 0,34 & Sin & NE \\
\hline Mollinedia clavigera Tul. & 6 & 0,09 & 0,14 & 0,08 & 0,31 & Sta & NE \\
\hline Mollinedia triflora (Spreng.) Tul. & 4 & 0,09 & 0,14 & 0,03 & 0,27 & Cli & NE \\
\hline Marlierea krapovickae D.Legrand & 5 & 0,09 & 0,14 & 0,02 & 0,26 & Cli & EN \\
\hline Miconia cabucu Hoehne & 8 & 0,09 & 0,07 & 0,07 & 0,23 & Pio & $\mathrm{NE}$ \\
\hline Zollernia ilicifolia (Brongn.) Vogel & 10 & 0,09 & 0,07 & 0,05 & 0,21 & Sta & $\mathrm{NE}$ \\
\hline Ilex brevicuspis Reissek & 11 & 0,09 & 0,07 & 0,04 & 0,21 & $\operatorname{Sin}$ & NE \\
\hline Solanum sanctae-catharinae Dunal & 8 & 0,09 & 0,07 & 0,04 & 0,2 & Sin & NE \\
\hline Ficus adhatodifolia Schott in Spreng. & 6 & 0,09 & 0,07 & 0,04 & 0,2 & Sta & NE \\
\hline Ocotea lanata (Nees \& Mart.) Mez & 11 & 0,09 & 0,07 & 0,04 & 0,2 & $\operatorname{Sin}$ & NE \\
\hline Annona rugulosa (Schltdl.) H.Rainer & 11 & 0,09 & 0,07 & 0,03 & 0,2 & Sta & NE \\
\hline $\begin{array}{l}\text { Allophylus edulis (A.St.-Hil. et al.) Hieron. } \\
\text { ex Niederl. }\end{array}$ & 5 & 0,09 & 0,07 & 0,02 & 0,18 & Sin & NE \\
\hline
\end{tabular}


TABELA 1: Continua...

TABLE 1 Continued...

\begin{tabular}{llllllll}
\hline Espécie & H & FR & DR & DoR & VI & GE & CA \\
\hline Inga marginata Willd. & 8 & 0,09 & 0,07 & 0,02 & 0,18 & Sin & NE \\
Psidium cattleianum Sabine & 9 & 0,09 & 0,07 & 0,02 & 0,18 & Sta & NE \\
Plinia brachybotrya (D.Legrand) Sobral & 7 & 0,09 & 0,07 & 0,02 & 0,18 & Sta & NE \\
Posoqueria latifolia (Rudge) Schult. & 10 & 0,09 & 0,07 & 0,02 & 0,18 & Sin & LC \\
Calyptranthes grandifolia O.Berg & 9 & 0,09 & 0,07 & 0,01 & 0,18 & Cli & NE \\
Casearia decandra Jacq. & 15 & 0,09 & 0,07 & 0,01 & 0,18 & Sin & NE \\
Myrsine umbellata Mart. & 8 & 0,09 & 0,07 & 0,01 & 0,18 & Sin & NE \\
Psychotria suterella Müll.Arg. & 3 & 0,09 & 0,07 & 0,01 & 0,18 & Cli & NE \\
Machaerium stipitatum (DC.) Vogel & 11 & 0,09 & 0,07 & 0,01 & 0,18 & Pio & NE \\
Inga vera Willd. & 13 & 0,09 & 0,07 & 0,01 & 0,17 & Pio & NE \\
Eugenia multicostata D.Legrand & 7 & 0,09 & 0,07 & 0,01 & 0,17 & Cli & NE \\
Myrcia anacardiifolia Gardner & 7 & 0,09 & 0,07 & 0,01 & 0,17 & Sta & NE \\
Myrsine coriacea (Sw.) R.Br. ex Roem. \& Schult. & 9 & 0,09 & 0,07 & 0,01 & 0,17 & Sin & NE \\
Myrcia hebepetala DC. & 7 & 0,09 & 0,07 & 0,01 & 0,17 & Sta & NE \\
Casearia obliqua Spreng. & 5 & 0,09 & 0,07 & 0,01 & 0,17 & Pio & NE \\
Bunchosia maritima (Vell.) J.F.Macbr. & 7 & 0,09 & 0,07 & 0,01 & 0,17 & Sta & LC \\
Cordia trichotoma (Vell.) Arrab. ex Steud. & 8 & 0,09 & 0,07 & 0,01 & 0,17 & Pio & NE \\
Eugenia bacopari D.Legrand & 9 & 0,09 & 0,07 & 0,01 & 0,17 & Sta & NE \\
Leandra dasytricha (A.Gray) Cogn. & 3 & 0,09 & 0,07 & 0,01 & 0,17 & Sin & NE \\
Myrcia calumbaensis Kaiersk. & 6 & 0,09 & 0,07 & 0,01 & 0,17 & Cli & NE \\
Myrcia tijucensis Kiaersk. & 6 & 0,09 & 0,07 & 0,01 & 0,17 & Cli & LC \\
Psychotria leiocarpa Cham. \& Schltdl. & 7 & 0,09 & 0,07 & 0,01 & 0,17 & Sta & NE \\
\hline Total & & 100 & 100 & 100 & 300 & & \\
\hline
\end{tabular}

Em que: $\mathrm{H}=$ altura máxima $(\mathrm{m}) ; \mathrm{FR}=$ frequência relativa $(\%)$; DR = densidade relativa (\%); DoR = dominância relativa (\%); VI = valor de importância; grupo ecológico (GE) em que: Pio = pioneira; Sin = secundária inicial; Sta = secundária tardia; $\mathrm{Cli}=$ clímax; categorias de ameaça (CA) em que: EN = Em Perigo; VU $=$ Vulnerável; NT = Quase Ameaçada; $\mathrm{LC}=$ Pouco Preocupante; NE = Não avaliada quanto à ameaça.

A elevada riqueza de espécies arborescentes amostradas no PEMJM, quando comparada com outros fragmentos florestais da região (CITADINI-ZANETTE, 1995; MARTINS, 2005; 2010; REBELO, 2006; COLONETTI et al., 2009; PASETTO, 2011; CITADINI-ZANETTE et al., 2014; BOSA et al., 2015), se deve, entre outros fatores, ao interesse dos moradores do entorno do Parque e a seu antigo proprietário, que optaram por sua conservação. Porém, diferentemente de outros estudos realizados na região sul de Santa Catarina, que apresentaram elevado valor de importância de Euterpe edulis (CITADINI-ZANETTE, 1995; SANTOS, 2003; MARTINS et al., 2013; CITADINI-ZANETTE et al., 2014; BOSA et al., 2015; GUISLON, 2017), no presente estudo, esta espécie não foi amostrada. A ausência de E. edulis no levantamento é explicada pelas alterações que o fragmento estudado sofreu em épocas passadas para a exploração de espécies com elevado valor econômico e alimentício, muito difundido na cultura regional. Klein (1990) destacou a alta densidade da espécie para a Floresta Atlântica (de 30 a 50\% dos indivíduos do interior da floresta), característica que permanece atualmente em outros fragmentos (ELIAS et al., 2016).

Reportando aos gêneros Myrcia (11 espécies) e Eugenia (oito), que neste estudo apresentaram maior riqueza específica em fragmentos florestais urbanos no sul de Santa Catarina, Pacheco (2010) registrou seis espécies para Myrcia e seis para Eugenia, enquanto Citadini-Zanette et al. (2014) encontraram oito e sete espécies, respectivamente. Além disso, Citadini-Zanette et al. (2003), em estudo mais abrangente da 
família Myrtaceae no sul de Santa Catarina, registraram 64 espécies em 14 gêneros de Myrtaceae, no qual Eugenia foi o gênero mais representativo, com 19 espécies, seguido por Myrcia, com 16 espécies. Segundo Chaves et al. (2009), Eugenia e Myrcia compreendem o maior número de espécies nativas de Myrtaceae, conferindo importante papel nas florestas brasileiras.

O fragmento florestal do PEMJM apresentou maior similaridade com o estudo realizado por Colonetti et al. (2009) (Tabela 2) em Floresta Ombrófila Densa Submontana em Siderópolis, com 61\% de espécies comuns, no entanto, comparando o presente estudo com o realizado por Pacheco (2010) em um fragmento urbano florestal no município de Criciúma e localizado mais próximo do PEMJM, pôde-se observar que, embora as áreas apresentem similaridade, esta última é menor (29\%), ocasionada, possivelmente, pela perturbação ocorrida no passado, o que resultou em estágios sucessionais distintos no interior da floresta, com reflexo na vegetação.

TABELA 2: Índices de similaridade de Jaccard entre os remanescentes de vegetação arborescente do bioma Mata Atlântica no sul de Santa Catarina, em que, FODM = Floresta Ombrófila Densa Montana, FODS = Floresta Ombrófila Densa Submontana, $\mathrm{Ne}=$ número de espécies arborescentes amostradas.

TABLE 2: Jaccard similarity index among the arboreal vegetation of the Atlantic Forest biome in southern Santa Catarina State, where, FODM = Montane Dense Ombrophilous Forest Montane, FODS = Submontane Dense Ombrophilous Forest, $\mathrm{Ne}=$ number of tree species sampled.

\begin{tabular}{|c|c|c|c|c|c|c|c|c|c|}
\hline Estudos & Formação & Município & Latitude & Longitude & $\begin{array}{l}\text { Altitude } \\
(\mathrm{m})\end{array}$ & $\mathrm{Ne}$ & & & \\
\hline Martins (2010) & FODM1 & Timbé do Sul & $28^{\circ} 44^{\prime}$ & $49^{\circ} 50^{\prime}$ & 500 & 149 & & & \\
\hline Bosa et al. (2015) & FODM2 & $\begin{array}{l}\text { Morro } \\
\text { Grande }\end{array}$ & $28^{\circ} 44^{\prime}$ & $49^{\circ} 45^{\prime}$ & 430 & 100 & & & \\
\hline Pasetto (2011) & FODM3 & Orleans & $28^{\circ} 11^{\prime}$ & $49^{\circ} 25^{\prime}$ & 550 & 128 & & & \\
\hline $\begin{array}{c}\text { Citadini-Zanette } \\
\text { (1995) }\end{array}$ & FODS1 & Orleans & $28^{\circ} 21^{\prime}$ & $49^{\circ} 17^{\prime}$ & 270 & 112 & & & \\
\hline Martins (2005) & FODS2 & Siderópolis & $28^{\circ} 35^{\prime}$ & $49^{\circ} 25^{\prime}$ & 140 & 115 & & & \\
\hline Rebelo (2006) & FODS3 & Laguna & $28^{\circ} 29^{\prime}$ & $48^{\circ} 53^{\prime}$ & 150 & 122 & & & \\
\hline $\begin{array}{l}\text { Colonetti et al. } \\
\text { (2009) }\end{array}$ & FODS4 & Siderópolis & $28^{\circ} 36^{\prime}$ & $49^{\circ} 33^{\prime}$ & 170 & 107 & & & \\
\hline Este estudo & FODS5 & Criciúma & $28^{\circ} 48^{\prime}$ & $49^{\circ} 25^{\prime}$ & 34 & 137 & & & \\
\hline $\begin{array}{l}\text { Citadini-Zanette } \\
\text { et al. (2014) }\end{array}$ & FODS6 & Turvo & $28^{\circ} 54^{\prime}$ & $49^{\circ} 41^{\prime}$ & 32 & 133 & & & \\
\hline \multicolumn{10}{|c|}{ Índices de similaridade de Jaccard } \\
\hline & FODM1 & FODM2 & FODM3 & FODS1 & FODS2 & FODS3 & FODS4 & FODS5 & FODS6 \\
\hline FODM1 & 1 & & & & & & & & \\
\hline FODM2 & 0,44 & 1 & & & & & & & \\
\hline FODM3 & 0,31 & 0,28 & 1 & & & & & & \\
\hline FODS1 & 0,3 & 0,33 & 0,29 & 1 & & & & & \\
\hline FODS2 & 0,33 & 0,37 & 0,28 & 0,75 & 1 & & & & \\
\hline FODS3 & 0,3 & 0,31 & 0,22 & 0,51 & 0,53 & 1 & & & \\
\hline FODS4 & 0,41 & 0,43 & 0,29 & 0,5 & 0,49 & 0,44 & 1 & & \\
\hline FODS5 & 0,36 & 0,41 & 0,28 & 0,54 & 0,59 & 0,46 & 0,61 & 1 & \\
\hline FODS6 & 0,35 & 0,34 & 0,3 & 0,32 & 0,33 & 0,3 & 0,38 & 0,36 & 1 \\
\hline
\end{tabular}

Pela presença de fragmentos florestais em estágio avançado de sucessão em uma região, pode-se inferir que ainda existe uma amostra da comunidade original. No entanto, para Rankin-de-Merona e Ackerly (1987), depois do isolamento, ocorrem mudanças no microclima e na própria estrutura física do fragmento, 
as quais exercem influências sobre as espécies restantes e que podem ser, eventualmente, refletidas em mudanças na composição taxonômica e demográfica futuras. O componente de maior visibilidade formado pelas árvores pode levar décadas ou mesmo séculos para responder à fragmentação. De fato, árvores podem viver por séculos e, embora vivas dentro de um fragmento, podem não mais estar se reproduzindo com a mesma intensidade e frequência anterior à fragmentação ou ao isolamento e, assim, são caracterizadas como indivíduos mortos-vivos; ao contrário, espécies vegetais de vida curta podem responder imediatamente à fragmentação (SCARIOT et al., 2003).

Quanto ao grau de vulnerabilidade, a maioria das espécies registradas foi categorizada como NE (Não avaliada quanto à ameaça) seguida por LC (Pouco Preocupante). No entanto, algumas espécies com elevado grau de ameaça foram amostradas no presente estudo, entre elas: Ocotea odorifera, Virola bicuhyba, Marlierea krapovickae (EN - Em Perigo) e Cedrela fissilis, Neomitranthes cordifolia e Myrciaria plinioides (VU - Vulnerável). A presença de espécies que tiveram o status de "Em Perigo" e "Vulnerável", remete à necessidade de políticas públicas focadas na restauração ambiental, que possibilitem reverter o quadro de vulnerabilidade, pois é possível aumentar o tamanho populacional de espécies ameaçadas, desde que sejam melhoradas as condições ecológicas dos ambientes degradados (SEVEGNANI et al., 2013) e que estas espécies sejam protegidas em Unidades de Conservação.

Entre as espécies encontradas, Cryptocarya moschata apresentou o maior valor de importância, sobretudo em função de seu alto valor de dominância, também ressaltado por Sevegnani (2003) em um levantamento fitossociológico na floresta do Parque Natural Municipal São Francisco de Assis, Blumenau-SC. Entre as 10 primeiras espécies com maior valor de importância, a elevada dominância também determinou as posições de Psychotria vellosiana, Matayba guianensis, Aspidosperma parvifolium e Alchornea triplinervia, enquanto a elevada densidade e/ou a alta frequência determinou as posições de Myrcia pubipetala, Alsophila setosa, Cabralea canjerana e Sorocea bonplandii.

Destacaram-se, com reduzida densidade, as espécies que foram amostradas com apenas um indivíduo por hectare (31 espécies ou 23\%). Na Mata Atlântica, a raridade de espécies, sintetizada pela baixa densidade, é acentuada. Kageyama e Gandara (2000), em levantamentos nas florestas ombrófila e semidecídua do estado de São Paulo, concluíram que entre 20 a 50\% das espécies contêm apenas um indivíduo por hectare. Hubbel e Foster (1986) destacaram vários fatores que determinam a raridade de uma espécie, como a ocupação de pequena porção do habitat, condições de regeneração infrequente ou sem ocorrência, um recente processo de imigração da espécie para área de estudo ou ainda, de acordo com Jarenkow (1994), o estágio sucessional em que as florestas se encontram. Myrcia splendens, espécie secundária inicial, comum em ambientes alterados, aparece como rara em floresta primária (CITADINI-ZANETTE, 1995) e com densidade de 45 indivíduos por hectare no presente estudo.

As alturas estimadas variaram entre 1,3 e 20,0 m (Figura 3). Os maiores valores foram atribuídos a dois indivíduos de Aspidosperma parvifolium, com $20 \mathrm{~m}$, e a outros dois indivíduos, um de Marlierea eugeniopsoides e outro de Ocotea urbaniana, todos com $19 \mathrm{~m}$. O maior número de indivíduos amostrados se concentrou entre 5,1 e 10,0 m de altura, sendo este estrato da vegetação caracterizado, principalmente, pelas espécies de sub-bosque como Sorocea bonplandii, Myrcia splendens e Rudgea jasminoides, além de indivíduos jovens de Cryptocarya moschata, Psychotria vellosiana e Myrcia pubipetala. A últimas classes de altura podem ser caracterizadas pelas espécies de dossel, destacando-se: Alchornea triplinervia, Aspidosperma australe, Aspidosperma tomentosum, Aspidosperma parvifolium, Cecropia glaziovii, Cryptocarya moschata, Duguetia lanceolata, Magnolia ovata, Tetrorchidium rubrivenium, entre outras. 


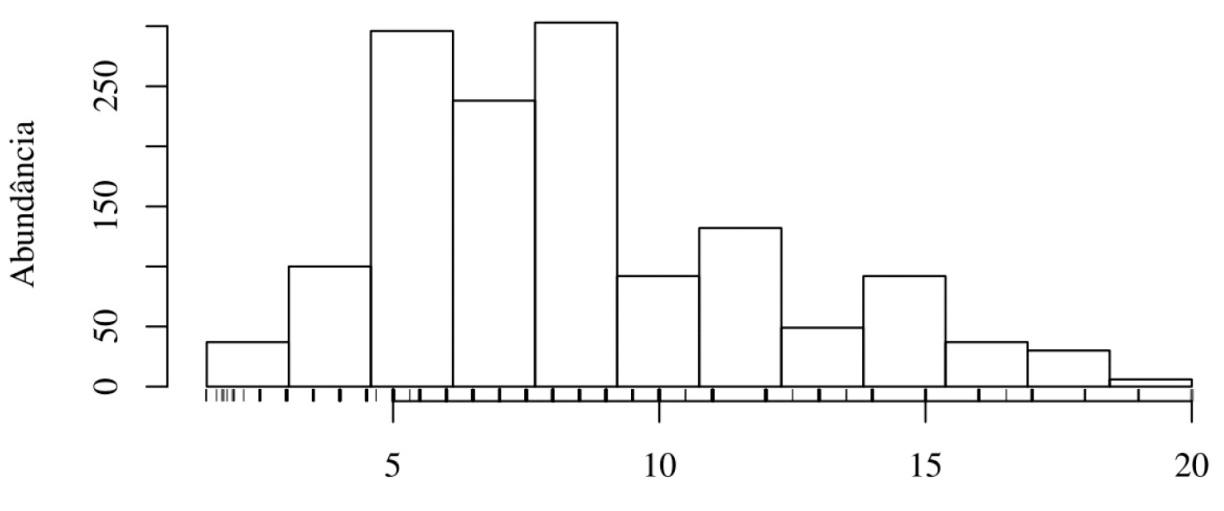

Altura (m)

FIGURA 3: Distribuição dos indivíduos arborescentes em classes de altura, a partir de 1,3 $\mathrm{m}$ de altura, em intervalos de 5 (cinco) metros de altura, de uma comunidade em fragmento urbano de Floresta Ombrófila Densa Submontana no município de Criciúma, estado de Santa Catarina, sul do Brasil.

FIGURE 3: Height classes of individual trees sampled in the phytosociological sampling, from $1.3 \mathrm{~m}$ high, at intervals of 5 (five) meters in height, in an urban fragment of Dense Ombrophilous Forest Submontane in the municipality of Criciúma, Santa Catarina State, southern Brazil.

Nas florestas urbanas estudadas por Pacheco (2010) e Citadini-Zanette et al. (2014) no sul de Santa Catarina, foram registrados maior número de indivíduos na classe de altura entre 5,1-11 m, com 74\% e 64\% dos indivíduos amostrados nesse intervalo de classe, respectivamente. Colonetti et al. (2009) e Bosa et al. (2015), em levantamentos da flora arbórea regional, encontraram, respectivamente, $73 \%$ e $87 \%$ das árvores concentradas em até $12,5 \mathrm{~m}$ de altura. Assim, observa-se que os estudos realizados no sul de Santa Catarina apresentam padrões semelhantes, estando a maioria dos indivíduos entre 5 a $12 \mathrm{~m}$ de altura. Segundo Souza et al. (2003), florestas naturais inequiâneas que se apresentam bem estratificadas suportam maior diversidade de biota, porque apresentam maior diferenciação de nichos, ou seja, nos estratos verticais dessas florestas, coexistem diferentes grupos de plantas e animais que ocupam diferentes nichos ecológicos, refletindo na riqueza, diversidade, crescimento e produção de biomassa (ARRUDA, 2010).

Os valores de diâmetro variaram de 5,0 a $76,5 \mathrm{~cm}$, sendo o maior valor obtido no fuste de um indivíduo de Aspidosperma parvifolium. A distribuição dos indivíduos por classe de diâmetro (Figura 4) indicou que a maioria das árvores amostradas $(65 \%)$ se concentrou na primeira classe, com valores compreendidos entre 5,0 e 9,9 cm. Apenas 20 indivíduos (1,4\%) apresentaram diâmetro igual ou superior a $45 \mathrm{~cm}$. 


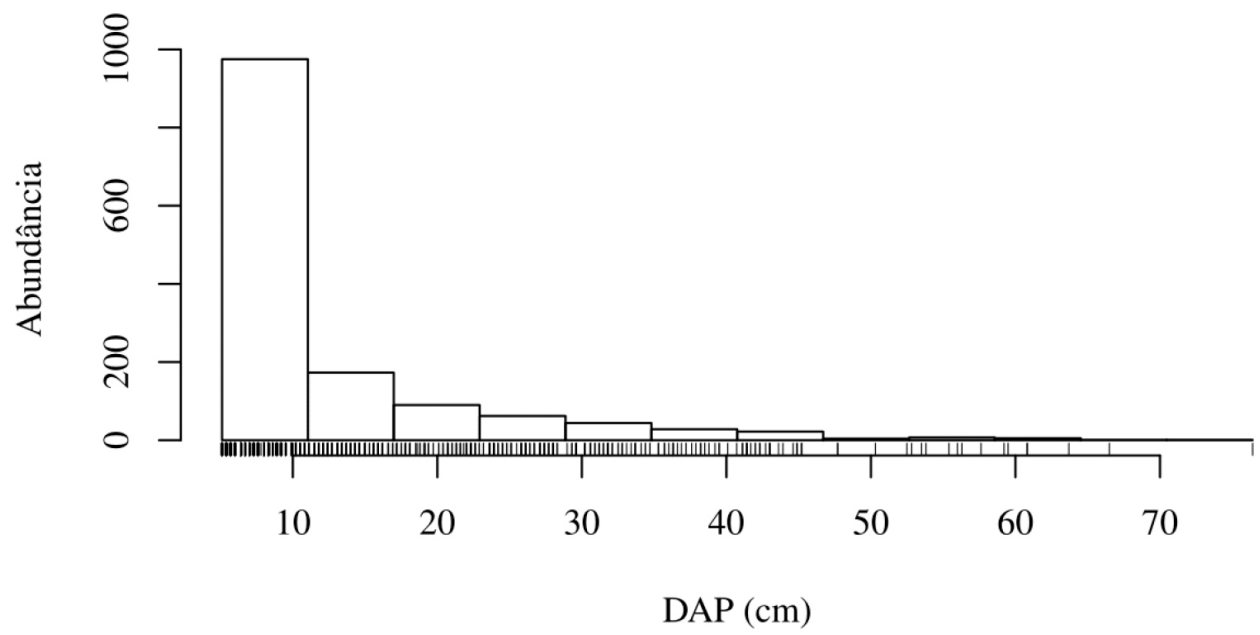

FIGURA 4: Distribuição dos indivíduos arborescentes em classes de diâmetro, em intervalos de 6 (seis) cm, de uma comunidade em fragmento urbano de Floresta Ombrófila Densa Submontana no município de Criciúma, estado de Santa Catarina, sul do Brasil.

FIGURE 4: Distribution of the number of individual trees sampled by diameter classes, at intervals of 6 (six) $\mathrm{cm}$, in an urban fragment of Dense Ombrophilous Forest Submontane in the municipality of Criciúma, Santa Catarina State, southern Brazil.

Com relação à área basal total, no presente estudo, obteve-se $28 \mathrm{~m}^{2} \cdot \mathrm{ha}^{-1}$, podendo ser considerada baixa em comparação à obtida por Jarenkow (1994), Santos (2003) e Citadini-Zanette (1995), que obtiveram $50 \mathrm{~m}^{2}$.ha- $\mathrm{a}^{-1}, 42 \mathrm{~m}^{2}$.ha-1 e $39 \mathrm{~m}^{2}$.ha-1, respectivamente. Entretanto, o valor obtido no presente estudo é superior ao encontrado por Santos (2003) para um fragmento em estágio médio de regeneração $\left(24,6 \mathrm{~m}^{2}\right.$.ha $\left.\mathrm{ha}^{-1}\right)$.

No estudo de Colonetti et al. (2009), os valores de diâmetro variaram de 5,1 a 140,4 cm, sendo o maior valor obtido por Ficus luschnathiana, com $55 \%$ dos indivíduos com valores inferiores a $10 \mathrm{~cm}$ e $1 \%$ com diâmetros dos caules iguais ou superiores a $45 \mathrm{~cm}$. Pacheco (2010) registrou a concentração de $63 \%$ dos indivíduos na primeira classe de diâmetro $(5,0-9,9 \mathrm{~cm})$ e apenas $0,4 \%$ apresentaram valores superiores a $40 \mathrm{~cm}$, sendo o maior valor obtido de $56 \mathrm{~cm}$ para Ocotea puberula. Citadini-Zanette et al. (2014) também registraram muitos diâmetros inferiores a $10 \mathrm{~cm}(55 \%)$ e apenas $2 \%$ dos indivíduos com valores superiores a $45 \mathrm{~cm}$, estando o maior valor superior a $80 \mathrm{~cm}$ (dois indivíduos). Esses resultados revelam o padrão de "J invertido", encontrado em populações naturais que possuem alta regeneração in loco, frequentemente observado em E. edulis (REIS, 1996; ROCHA, 2004).

Com base na dinâmica sucessional apresentada por Klein (1980) para o estado de Santa Catarina, na Resolução CONAMA 004/94 (BRASIL, 1994), na composição florística e estrutural da comunidade arborescente amostrada, é possível inferir que o fragmento estudado não teve alterações recentes, após ter sofrido, em épocas passadas, processo de corte seletivo, principalmente de espécies madeireiras e de palmiteiros.

\section{CONCLUSÃO}

O fragmento florestal no qual foi realizado o presente estudo possui elevada riqueza específica, sobretudo de Myrtaceae e Lauraceae, se comparado com outros remanescentes na região, tornando-o uma importante fonte de diásporos para áreas adjacentes, em estágios sucessionais menos avançados.

O conhecimento produzido a partir deste estudo poderá fornecer alternativas de uso e manejo em áreas similares, ou mesmo, ambientes florestais alterados, de forma geral. Por meio das informações obtidas a partir do levantamento, além de se ampliar os dados sobre a biodiversidade regional, estes servirão para 
subsidiar a restauração de fragmentos de Floresta Ombrófila Densa, pela indicação de espécies de diferentes grupos ecológicos. Adicionalmente, a detecção de espécies com maior valor de importância também poderá contribuir para a seleção de espécies em ações de restauração florestal no perímetro urbano.

Fragmentos florestais urbanos não podem ser manejados do mesmo modo que uma área contínua, em que as medidas de conservação devem ser distintas. Enquanto em áreas urbanas, em geral fragmentadas e impactadas, as ações de manejo e restauração tornam-se imperativas, em áreas contínuas e afastadas dos centros urbanos estas podem ser aplicadas de forma menos intensa, dependendo do caso.

\section{REFERÊNCIAS}

ALVARES, C. A. et al. Köppen's climate classification map for Brazil. Meteorologische Zeitschrift, v. 22, n. 6, p. 711-728, 2013.

ANGIOSPERM PHYLOGENY GROUP. The Angiosperm Phylogeny Group. An update of the Angiosperm Phylogeny Group classification for the orders and families of flowering plants: APG IV. Botanical Journal of the Linnean Society, London, v. 181, n. 1, p. 1-20, 2016.

ARRUDA, C. R. Determinação de unidades de gestão em floresta natural, no município de Jaína, Mato Grosso. 2010. 75 f. Dissertação (Mestrado em Ciências Ambientais e Florestais) - Universidade Federal do Mato Grosso, Cuiabá, 2010.

BOSA, D. M. et al. Florística e estrutura do componente arbóreo de uma Floresta Ombrófila Densa Montana em Santa Catarina, Brasil. Revista Árvore, Viçosa, MG, v. 39, n. 1, p. 49-58, 2015.

BRASIL. CONAMA. Resolução do CONAMA n ${ }^{0}$. 004, de 4 de maio de 1994. Publicação DOU n ${ }^{0} 114$, de 17/06/1994, pág. 8877-8878. Disponível em: <http://www.mma.gov.br/port/conama/legiano1>. Acesso em: 19 ago. 2015.

BRITEZ, R. M. et al. Manejo do entorno. In: RAMBALDI, D. M.; OLIVEIRA, D. A. S. (Org.). Fragmentação de Ecossistemas: causas, efeitos sobre a biodiversidade e recomendações de políticas públicas. Brasília: MMA; SBF, 2003. p. 347-365.

CHAVES, C. L. et al. Espécies nativas de Myrtaceae em fragmentos de Floresta Ombrófila Mista no município de Ponte Alta, Santa Catarina. In: CONGRESSO DE ECOLOGIA DO BRASIL, 9., São Lourenço, 2009. Anais... São Lourenço: [s. n.], 2009.

CITADINI-ZANETTE, V. Florística, fitossociologia e aspectos da dinâmica de um remanescente de Mata Atlântica na microbacia do Rio Novo, Orleans, SC. 1995. 236 f. Tese (Doutorado em Ecologia) Universidade Federal de São Carlos, São Carlos, 1995.

CITADINI-ZANETTE, V. et al. Composição florística de um fragmento florestal ciliar no Sul de Santa Catarina. Revista Tecnologia e Ambiente, Criciúma, v. 20, p. 55-70, 2014.

CITADINI-ZANETTE, V. et al. Myrtaceae do sul de Santa Catarina: subsídio para recuperação de ecossistemas degradados. Revista Tecnologia e Ambiente, Criciúma, v. 9, n. 2, p. 61-75, 2003.

COLONETTI, S. et al. Florística e estrutura fitossociológica em floresta ombrófila densa submontana na Barragem do Rio São Bento, Siderópolis, Estado de Santa Catarina. Acta Scientiarum, Biological Science, Maringá, v. 31, n. 4, p. 337-458, 2009.

DACANAL, C.; LABAKI, L. C.; SILVA, T. Vamos passear na floresta! O conforto térmico em fragmentos florestais urbanos. Ambiente Construído, Porto Alegre, v. 10, n. 2, p. 115-132, 2010.

DUFLOTH, J. H. et al. (Org.). Estudos básicos regionais de Santa Catarina, Florianópolis: Epagri, 2005. CD-ROM.

ELIAS, G. A. et al. Community Structure of Large Native Arborescent Palms (Arecaceae) using data from the Floristic and Forest Inventory of Santa Catarina, Brazil. Australian Journal of Basic and Applied Sciences, Amman, v. 10, p. 156-163, 2016.

EMPRESA DE PESQUISA AGROPECUÁRIA E DE EXTENSÃO RURAL DE SANTA CATARINA. Dados e informações bibliográficas da unidade de planejamento regional litoral sul catarinense-UPR8. Florianópolis: EPAGRI, 2001. 1 CD ROM.

FERRETTI, A. R. et al. Classificação das espécies arbóreas em grupos ecológicos para revegetação com nativas no Estado de São Paulo. Florestar Estatístico, São Paulo, v. 3, n. 7, p. 73-77, 1995.

FISZON, J. T. et al. Causas antrópicas. In: RAMBALDI, D. M.; OLIVEIRA, D. A. S. (Org.). Fragmenta- 
ção de Ecossistemas: causas, efeitos sobre a biodiversidade e recomendações de políticas públicas. Brasília: MMA; SBF, 2003. p. 66-99.

GÓMEZ-POMPA, A.; WIECHERS, B. L. Regeneración de los ecossistemas tropicales y subtropicales. In: GÓMEZ-POMPA, A.; AMO, R. S. (Ed.). Investigaciones sobre la regeneración de las selvas altas en Vera Cruz, México. Cidade do México: Continental, 1979. p. 11-30.

GUISLON, A. V. Comunidade arbórea e histórico de ocupação humana em uma Floresta Ombrófila Densa Montana no Sul do Brasil. 2017. 102 p. Tese (Mestrado em Ciências Ambientais) - Universidade do Extremo Sul Catarinense, Criciúma, 2017.

HUBBELL, S. P.; FOSTER, R. B. Commonness and rarity in a neotropical forest: implications for tropical tree conservation. In: SOULE, M. E. Conservation biology: the science of scarcity and diversity. Sunderland: Sinauer Associate, 1986. p. 205-231.

HULTMAN, S. Urban Forests in Sweden: their use for recreation and timber Growing. In: TREES AND FORESTS FOR HUMAN SETTLEMENTS, 1976. Proceedings... Toronto: IUFRO, 1976. p. 36-42.

JARENKOW, J. A. Estudo fitossociológico comparativo entre duas áreas com mata de encosta no Rio Grande do Sul. 1994. 122 f. Tese (Doutorado em Ecologia e Recursos Naturais) - Universidade Federal de São Carlos, São Carlos, 1994.

KAGEYAMA, P. Y.; GANDARA, F. B. Recuperação de formações ciliares. In: RODRIGUES, R. R.; LEITÃO-FILHO, H. F. (Ed.). Matas ciliares: conservação e recuperação. São Paulo: EDUSP; FAPESP, 2000. p. 249-270.

KAGEYAMA, P. Y.; GANDARA, F. B.; SOUZA, L. M. I. Consequências genéticas da fragmentação sobre populações de espécies arbóreas. Série Técnica IPEF, Piracicaba, v. 2, n. 32, p. 65-70, 1998.

KERSTEN, R. A.; GALVÃO, F. Suficiência amostral em inventários florísticos e fitossociológicos. In: FELFILI, J. M. et al. Fitossociologia no Brasil: métodos e estudos de casos. Viçosa, MG: Ed. UFV, 2011. p. 156-173.

KLEIN, R. M. Ecologia da flora e vegetação do Vale do Itajaí. Sellowia, Itajaí, v. 31/32, p. 1-389, 1980.

KLEIN, R. M. Estrutura, composição florística, dinamismo e manejo da "Mata Atlântica" (Floresta Ombrófila Densa) do Sul do Brasil. In: SIMPÓSIO DE ECOSSISTEMAS DA COSTA SUL E SUDESTE BRASILEIRA, 2., Águas de Lindóia,1990. Anais... Águas de Lindóia: [s. n.], 1990. v. 1. p. 259-86.

LEITE, P. F.; KLEIN, R. M. Vegetação. In: IBGE. Geografia do Brasil. Rio de Janeiro: IBGE, 1990. v. 2. p. 113-150.

MAGURRAN, A. E. Ecological diversity and its measurement. Malden: Blackwell Science, 2004. 215 p. MARTINELLI, G.; MORAES, M. A. (Org.). Livro vermelho da flora do Brasil. Rio de Janeiro: Instituto de Pesquisas Jardim Botânico do Rio de Janeiro, 2013. 1002 p.

MARTINS, R. Florística, estrutura fitossociológica e interações interespecíficas de um remanescente de Floresta Ombrófila Densa como subsídio para recuperação de áreas degradadas pela mineração de carvão, Siderópolis, SC. 2005. 94 f. Dissertação (Mestrado em Biologia Vegetal) - Universidade Federal de Santa Catarina, Florianópolis, 2005.

MARTINS, R. Composição e estrutura vegetacional em diferentes formações na Floresta Atlântica, sul de Santa Catarina, Brasil. 2010. 148 f. Tese (Doutorado em Botânica) - Universidade Federal do Rio Grande do Sul, Porto Alegre, 2010.

MARTINS, R. et al. Estrutura de uma floresta brejosa em substrato turfoso, Sul de Santa Catarina, Brasil. Revista Árvore, Viçosa, MG, v. 37, n. 2, p. 299-309, 2013.

METZGER, J. P. O que é ecologia de paisagens? Biota Neotropica, São Paulo, v. 1, n. 1/2, p. 1-9, 2001.

MILLER, R. W. Urban Forestry: planning and managing urban green spaces. 2nd ed. Long Grove: Waveland, 2007.

MORELLATO, P. C.; LEITÃO-FILHO, H. F. (Org.). Ecologia e preservação de uma Floresta Tropical Urbana: Reserva Santa Genebra. Campinas: Unicamp, 1995. 136 p.

MUELLER-DOMBOIS, D.; ELLENBERG, H. Aims and methods of vegetation ecology. 2nd ed. New Jersey: The Blackburn Press, 2002. 547 p.

PACHECO, D. Planejamento para infraestrutura de trilha em fragmento florestal urbano no município de Criciúma, Santa Catarina. 2010. 80 f. Dissertação (Mestrado em Ciências Ambientais) - Universidade do Extremo Sul Catarinense, Criciúma, 2010. 
PASETTO, M. R. Composição florística e chave de identificação vegetativa das espécies arbóreas do Parque Estadual da Serra Furada, SC. 2011.68 f. Dissertação (Mestrado em Ciências Ambientais) - Universidade do Extremo Sul Catarinense, Criciúma, 2011.

PIELOU, E. C. Ecological diversity. New York: Wiley, 1975. 165 p.

PRIMACK, R. B.; RODRIGUES, E. Biologia da conservação. Londrina: E. Rodrigues, 2001. 328 p.

RANKIN-DE-MERONA, J. M.; ACKERLY, D. D. Estudos populacionais de árvores em florestas fragmentadas e as implicações para conservação In Situ das mesmas na Floresta Tropical da Amazônia Central. IPEF, Piracicaba, n. 35, p. 47-59, 1987.

REBELO, M. A. Florística e fitossociologia de um remanescente florestal ciliar: subsídio para a reabilitação de vegetação ciliar para microbacia do rio Três Cachoeiras, Laguna, SC. 2006. 143 f. Dissertação (Mestrado em Ciências Ambientais) - Universidade do Extremo Sul Catarinense, Criciúma, 2006. REIS, A. et al. Demografia de Euterpe edulis Martius (Arecaceae) em uma Floresta Ombrófila Densa Montana em Blumenau, SC. Sellowia, Itajaí, v. 45/48, p. 13-45, 1996.

REITZ, R. Plano de coleção. In: REITZ, R. (Ed.). Flora Ilustrada Catarinense. Itajaí: Herbário Barbosa Rodrigues, 1965. p. 1-71.

ROCHA, E. Potencial ecológico para o manejo de frutos de açaizeiro (Euterpe precatoria Mart.) em áreas extrativistas no Acre, Brasil. Acta Amazonica, Manaus, v. 34, n. 2, p. 237-250, 2004.

SANTOS, R. Reabilitação de Ecossistemas Degradados pela Mineração de Carvão a Céu Aberto em Santa Catarina, Brasil. 2003. 115 f. Tese (Doutorado em Engenharia Mineral) - Universidade de São Paulo, São Paulo, 2003.

SCARIOT, A. et al. Vegetação e Flora. In: RAMBALDI, D. M.; OLIVEIRA, D. A. S. (Org.). Fragmentação de Ecossistemas: causas, efeitos sobre a biodiversidade e recomendações de políticas públicas. Brasília: MMA; SBF, 2003. p. 103-123.

SEVEGNANI, L. Dinâmica de população de Virola bicuhyba (Schott) Warb. (Myristicaceae) e fitossociologia de Floresta Pluvial Atlântica, sob clima temperado, Blumenau, SC. 2003. 195 f. Tese (Doutorado em Ciências) - Universidade de São Paulo, São Paulo, 2003.

SEVEGNANI, L. et al. Ameaças à biodiversidade. In: SEVEGNANI, L.; SCHROEDER, E. Biodiversidade catarinense: características, potencialidades e ameaças. Blumenau: Edifurb, 2013. p. 196-221.

SMITH, A. R. et al. Fern classification. In: RANKER, T. A.; HAUFLER, C. H. (Ed.). Biology and evolution of ferns and lycophytes. Cambridge: Cambridge University Press, 2008. p. 417-467.

SOUZA, D. R. et al. Emprego de análise multivariada para estratificação vertical de florestas inequiâneas. Revista Árvore, Viçosa, MG, v. 27, n. 1, p. 59-63, 2003.

VIBRANS, A. C. et al. Extensão original e atual da cobertura florestal de Santa Catarina. In: VIBRANS, A. C. et al. (Ed.). Diversidade e conservação dos remanescentes florestais. Blumenau: Edifurb, 2012. p. $65-78$. 